\title{
Pandemic Pivots: The Impact of a Global Health Crisis on the Dissertation in Practice
}

\author{
Cassidy Alvarado \\ Loyola Marymount University \\ cassidy.alvarado@lmu.edu \\ Leyda Garcia \\ Loyola Marymount University \\ lgarci84@lion.lmu.edu \\ Nikysha Gilliam \\ Loyola Marymount University \\ ngillia1@lion.lmu.edu \\ Sydney Minckler \\ Loyola Marymount University \\ sminckle@lion.lmu.edu \\ Csilla Samay \\ Loyola Marymount University \\ csilla.samay@lmu.edu
}

\begin{abstract}
Five scholarly practitioners in an educational leadership for social justice doctoral program share their intentional, community-minded pivots during a global pandemic that disrupted their Dissertations in Practice (DiP). Embodying their Ed.D. program's CPED framework (Carnegie Project on the Education Doctorate, 2019), the authors, at varying stages in the dissertation process, sought inventive solutions to COVID-19-related challenges that included the development of a new topic and research questions, adjusting study settings and participant pools, and embracing new methodologies to account for virtual-only approaches. Although uncertain how the global health crises would impact their DiP, by fostering a shared sense of community, the authors became critical friends, supporting each other in their personal, professional, and academic lives. Each narrative highlights the potential of oppositional praxis of threading identities of practice, reflection, and research-to respond creatively to the needs of their diverse research communities with compassion, vision, and agility.
\end{abstract}

\section{KEYWORDS}

research pivot, dissertation in practice, community-based research, covid-19 pandemic, critical friend support

\section{INTRODUCTION}

As scholarly practitioners in the fifteenth cohort of a doctoral program in educational leadership for social justice, we began the spring semester of 2020 preparing for our proposal defenses. With a curriculum grounded in the CPED framework, faculty continued to push us to "develop a critical and professional stance with a moral and ethical imperative for equity and social justice" (Carnegie Project on the Education Doctorate, 2019). Drawing from our own extensive experience as full-time educators, we developed dissertation topics 4 centered on social justice issues, incorporating both theoretical and 4 applied, field-based research methods-a cornerstone of the professional doctorate in education programs. Although our problems of practice are unique to our individual professional contexts (our dissertations include domestic and international studies across K-12 and higher education settings), we became critical friends, supporting each other's work (Carnegie Project on the Education Doctorate, 2019). However, in March 2020, COVID-19 forced us to pivot-from radical topic and setting changes, to new methodologies and data collection approaches. Storey and Maughan (2016) note that "the research process should help the practitioner scholars combine research techniques with experiential knowledge and deepen their ability to think about problems and search for practical solutions simultaneously" (p. 225). The pandemic impacted our research at varying stages of the dissertation process, but
New articles in this journal are licensed under a Creative Commons Attribution 4.0 United States License. Program and is cosponsored by the University of Pittsburgh Press.

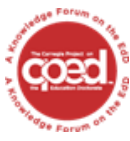

This journal is supported by the Carnegie Project on the Education Doctorate: A Knowledge Forum on the EdD (CPED) cpedinitiative.org 
through a shared sense of community and support for one another's scholarly and professional journeys, we responded by implementing practical solutions to complex problems that strengthened our capabilities. The following five examples highlight how we, as scholarly practitioners, responded creatively to the needs of our diverse communities through our Dissertations in Practice (DiP). Each narrative highlights the potential of oppositional praxis (Sandoval, 2000)-of threading identities of practice, reflection, and research-to respond creatively to the needs of diverse communities with compassion, vision, and agility.

\section{COVID Community}

During the spring semester of my second year in the doctoral program, and after several false starts, my dissertation was finally falling into place. I would investigate how parental participation was impacted by a school district's transition to digital communication. At the same time, COVID-19 began sweeping the world. When schools began to close, my chair and I realized that this topic would need to shift.

In the days following the closure, I was overwhelmed by my sense of loneliness due to the lack of interactions with students and other staff members. It was this loneliness and a desire to investigate how others were attempting to recreate the supportive physical school community that propelled me to a new topic. Additionally, I was noticing that even with teachers scrambling to create online educational experiences, some of our students, especially those already disengaged from school, were disappearing; I wanted to know why. This is when I pivoted to my new topic of building an eschool community during the emergency COVID-19 closure.

A student's sense of belonging at school has been positively linked to higher attendance and I pondered whether this would carry over into the digital realm (Frazier et al., 2015; Osterman, 2000). Since a student's sense of belonging to a school community can provide a safety net for early detection of mental health issues, and due to the sudden disruption of my students' lives, I was concerned about how this would be affected by emergency distance teaching (Frazier et al., 2015; Levitt et al., 2007). These concerns, along with my own desire to be a part of a community, drove my research as I raced to complete my proposal for the review committee. I successfully defended my proposal and started data collection in the summer.

I reached out to the school community with interview requests and was amazed at how quickly, even eagerly, people responded. I was concerned that conducting interviews with physical distance via the Zoom platform, the interviews might be less honest, less illuminating, and less connected. I have been gratefully surprised by the careful consideration given to my questions and the openness of their responses. Their willingness to engage with me in this research can be contributed to the community and relationships formed before the closure and maintained once separated.

I have been struck by the deep sense of loss the participants express. Using a three-part interview protocol, participants discuss the history of what our school community was before the closures, what it was like during the closure, and then reflect on the alterations since the closure. Preliminary findings suggest school staff is mourning the loss of student connections built from the daily physical interactions. They discuss handshakes, class discussions, and small moments of comfort that they miss. The teachers are lamenting their lack of skills in the digital classroom; their reduction in becoming a first-year teacher again coupled with the anxiety of the unknown. The technology coach has been alarmed by her loss of boundaries between work and family life. Thinking of the poverty present at the school site pre-COVID, the school psychologist worried about all the students who had no quiet, safe place to work, especially those in group home placement.

Parents too expressed their grief. Parents of eighth-grade students mourned the end-of-year events, the virtual promotion, and the lack of real goodbyes. Several parents cried recounting the loss of the school community and its effects on their children. After many interviews were concluded, the participants desired a debrief conversation to express the emotions unearthed by the interview.

Overall, the final question of the interview investigates views, thoughts, and concerns about the 2020-2021 school year. Every participant shared unique fears and concerns, but each response contained an aspect of uncertainty, a fear of the unknown, and unknowable. These fears, their sadness, and anxiety could be alleviated somewhat by a strong, supportive school community, but unfortunately, that community is still under construction.

\section{Student Voice and Agency}

School communities are microcosms of the larger society. In the previous narrative, the focus was on the impact of the pandemic on an entire school community. The relationships forged within that community were strained by the school's closure. Research, in the form of a case study, opened the door to spaces that helped capture that story while offering a way to reconnect. That is the power of research that answers to communities and thus leverages the production of knowledge to uplift (Patel, 2016). My own direct work with immigrant-origin youth has greatly informed how much respect and admiration I have for young people who leave home in search of a better life, in fulfillment of their dreams. The identities of these youth often defy the school system's narrow definitions of who they are. Labels such as English Learners or newcomers fail to capture their rich and complex identities, their political stances, and their influence on the spaces that seek to educate them. For my study of unaccompanied youth, I wanted to center their epistemology to inform emancipatory educational practices at school sites. I realized that the only way to honor the youth's complex identities was to include youth as co-researchers. My aim was to engage in research that answered to immigrant youth and was not simply about them.

Using CRT (Solorzano \& Yosso, 2002) and Youth Participatory Action Research (YPAR, Cammarota \& Fine, 2008) methodologies, the project sought to produce actionable items that could positively impact the school site and other educational agencies. However, by mid-March 2020, the pandemic meant that schools would not reopen for months.

This complicated the research project in ways that neither I nor the youth co-researchers could have anticipated. Before the school closure, four youth co-researchers were recruited to interview each other, interview other unaccompanied youth, hold a focus group, and review school documents as part of the data collection.

Due to COVID-19, the research project lost a common shared space: the school. The co-researchers were all enrolled in a research course and their class discussions and learning often spilled into our after-school meetings over pizza or chicken wings. The first draft of the interview protocol was created over breakfast in a small cafe where we discussed at length what would help us learn more about the unaccompanied youth identity and their experiences 
in school. The conversations we had were often grounded in a theoretical article on CRT (Solorzano \& Yosso, 2002). Taking those organic and rich discussions to a virtual space appeared to be close to impossible.

Secondly, student lives were greatly impacted by the pandemic. One of the youth co-researchers became the only source of income for her family. She continued cleaning houses for a few clients that felt safe enough to allow her into their homes. Another student traveled to San Jose to be with his older brothers. A third student became the babysitter for her nieces as her older brothers looked to save money when their own work hours were reduced. The fourth student had also lost his part-time employment at a car wash.

In late spring, I called a virtual meeting just to check in with the group. I was also feeling disconcerted and exhausted from working non-stop. We scheduled a second meeting and decided to rethink our design. As the principal investigator, I designed a deck of Google slides to help us organize our Zoom meetings and capture our learning. During those first few awkward meetings, the researchers and I realized that the community we had built in a physical space could continue in our virtual space. We agreed to continue our important work through weekly Zoom meetings. We opened every meeting with a short meditation to center ourselves and to focus our collective energy back on our project. The study was scaled back to include fewer interviews, no focus group due to scheduling difficulties, and I completed the document analysis.

In order to mitigate the difficulty of having virtual interviews, the team decided that we would always start with a check-in before the interview, to re-establish a sense of connection. This part was not recorded. The recording itself required additional creative steps. Often, the interview was conducted via a video call. The audio was recorded on the computer to protect the anonymity of the participant. The IRB did not include a video recording of the interview. This population of students is highly vulnerable and the team wanted to protect all the participants. For the data analysis, we had to create a shared Google drive that contained all the transcripts. I would often share my screen as a way for the team to conduct the first round of analysis. Padlets were used to do the initial coding of the data. This allowed the team to collaborate in real-time when needed. Virtual, collaborative tools allowed us to continue working together, without having to be in the same physical space. As the co-researchers' work schedules became more complicated, the team's ability to meet on a weekly basis dwindled. As the new school year neared I was even busier preparing for a new virtual school year.

In spite of all the challenges, the findings of the study yielded rich descriptions of the complicated identities of these immigrantorigin youth. The youth seamlessly navigate across all their identities through what Chela Sandoval (2000) refers to as differential consciousness, "a cyberspace, where the transcultural, transgendered, transsexual, transnational leaps necessary to the play of effective stratagems of oppositional praxis can begin" ( $p$. 68.8).

The essential question for public schools that seek to educate immigrant-origin youth is to consider how their current spaces can be more open and receptive to the voices of these youth. In the midst of a pandemic, scholarly practitioners with a social justice orientation must center their research in a way that is (a) responsive to the contexts under study and (b) leverages the knowledge production of marginalized voices, to foreground research as a liberatory force in education.

\section{Onward through Online Interviews}

Similar to my co-authors above, the challenge of building student trust and community in a virtual setting was not limited to K12 spaces. In response to the growing COVID-19 crisis, the university where I work moved to online instruction and I began working remotely from home. At this same time, I successfully passed my proposal defense and received IRB approval for my exploratory mixed methods study that seeks to understand community college transfer student awareness of nationally competitive awards (NCAs), like the Benjamin A. Gilman Scholarship and Fulbright U.S. Student Program. My plan had been to conduct in-person interviews with transfer students from one university. Before proceeding with my qualitative interviews, I needed to make some quick-thinking adjustments to account for the abrupt shift to a virtual modality.

Having confirmed a university site for my interview participant pool, I was eager to begin my data collection. Yet, I was concerned that students would be unavailable or unwilling to participate in a 45minute interview, considering they were experiencing abrupt life challenges such as moving back home and transitioning unexpectedly to online instruction. Moreover, I worried students would not be as open or honest in an online setting. To my surprise, over thirty transfer students expressed an interest in participating. This led to my first major pivot, conducting ten student interviews instead of my initial plan of five. This proved propitious given that after my interviews, when I was ready to disseminate my newly developed survey, two of my three confirmed sites apologetically withdrew their support, citing COVID-19 as the primary factor.

However, I knew that increasing the number of participants would not mitigate my concerns about authentic dialogue in an online space. This led to my second pivot in which I reexamined my interviewing approach to account for the new setting. Drawing from Noddings' (2013) ethics of care, I sought to "work cooperatively with the student in his struggle toward competence in that world" (p.177), which now included postponed graduations, job losses, and canceled summer internships. I began every interview by thanking them for their participation (Galletta \& Cross, 2013), followed by a question about their well-being. I also wanted to ensure participants felt comfortable with me even though we were communicating through a screen. Mann and Stewart (2000) expound on the importance of developing an enthusiastic rapport with online interview participants and recommend building trust by being open about the structure and purpose of the research. After my initial wellness check, I provided participants a clear outline of the topics we would discuss and paused for questions throughout. Students demonstrated a genuine interest in the study's focus and not one of the ten participants appeared reserved or reticent during the 45minute interviews. Online environments may in fact encourage shy individuals to speak more openly and freely because it's a "culturally neutral" space in which participants have chosen their physical location to engage in the research (Mann \& Stewart, 2000, p. 201). Thus, the virtual format may have actually elicited more thoughtful responses which often included COVID-19 as a topic of concern.

This led to a third pivot during my qualitative interviews, taking into account the impact of the pandemic on participant responses. Given that several of my exemplar NCAs, like Gilman and Fulbright, provide funding for study abroad or international research, it was likely that a student's interest in these opportunities may be influenced by the global health crisis. Because I employed a semi- 
structured phenomenological interview protocol, I was able to "rephrase the questions, and make changes according to the interview situation" (Galletta \& Cross, 2013, p. 75). I phrased questions in a way that allowed participants to consider their preCOVID-19 worldviews, such as when one participant stated that he no longer thought it was possible to study abroad due to the virus. I responded with "Yeah, we're in a very unique situation right now. When would you have liked to have gone abroad if everything had worked out?" I leaned into these responses, encouraging participants to explain how their situations may have changed, but also kept the focus on my research questions. Ultimately, several participants noted that COVID-19 had changed their plans to study or travel abroad. Yet, by creating a space that encouraged participants to express these changes, they were able to look beyond the pandemic and most expressed interest in future international opportunities.

Conducting qualitative interviews during a pandemic led to quick-thinking shifts in both the modality of the interview setting, as well as my questioning method and participant interactions. This led to intense self-reflection about the kind of researcher I want to be. Noddings (2013) notes that "the primary aim ... of every educational effort must be the maintenance and enhancement of caring" ( $p .175)$. I believe this extends to educational research and I have strived to situate caring as a primary characteristic of my DiP_especially after COVID-19's unpredictable impact.

\section{Research Left Behind}

I was preparing to defend my dissertation proposal on the experience of Muslim international students in the United States when COVID-19 hit the United States, turning my plans for defense and research upside down. As I navigated the tremendous disruptions in my personal and professional life, I realized that my research participants were having the same experience and I needed to approach my study with an even greater element of care for them.

After two years in my doctoral program, I can confirm the impact of doing a Dissertation in Practice on social justice in my professional endeavors. I provide leadership to our university's office supporting international students, and my dissertation work thus far had led me to engage in robust research on student support and rich conversation with students around their need for support and formation of a strong sense of community.

In 2019, international students comprised $5.5 \%$ of the total US higher education population (Institute for International Education [IIE], 2019); they are among the most heavily monitored populations in the immigration system as their visas require constant reporting of enrollment information. Offices that support international students on campus play a critical role in helping students maintain their student visa status, adjust to, and thrive in the American university environment. These offices should be staffed with colleagues who have adequate intercultural and international experiences to be able to understand and relate to the challenges of international students (Rao, 2017).

As our campus closed, our own international students faced travel restrictions, navigated online courses across time zones, experienced financial challenges, and struggled to stay current on regulations concerning their student visas. Public discourse around the relationship between many of their countries and the US added additional layers of tension. Past studies have identified international student concerns about the historical and political relationship between their countries and the US, leading to feelings of prejudice against them (Sherry et al., 2010). These feelings were heightened by the July 6, 2020 announcement from the US Government barring international students from returning to the US if their courses were fully on-line (US Immigration and Customs Enforcement, 2020).

Through the spring and summer, I provided leadership to my unit in responding to and supporting students and collaborated with senior administrators to join the subsequent and ultimately successful lawsuit filed by several other institutions to rescind the July 6 announcement. I composed communication with students to affirm their value to our institution, working in partnership with senior leaders and colleagues to make sure our international students' education would not be disrupted as the university decided on a fully online format for Fall 2020. Faculty were encouraged to develop asynchronous course content, we formed a partnership with the library to assist students overseas in accessing course materials, encouraged our academic resource center to hired tutors to support students from different time zones, and briefed the entire community on how best to support our international students. I worked personally with countless students and families at all hours of the day and evening, and my children's' frequent disruption of my video calls seemed to provide them with a measure of comfort, knowing we were all experiencing a major upheaval and were doing the best we could.

As most universities in our region began their fall semester entirely online, I realized the need to pivot and change my methodology and plans for data collection. No longer would I have the opportunity to invite participants to join in-person focus groups, nor would I be able to engage in the participant observation my ethnographic methodology required. I created a new plan for a phenomenological study, utilizing individual interviews with our Muslim international students, broadening my research questions to capture their individual lived experiences navigating this time of COVID-19. In particular, I included questions to explore how they navigated the demands of their courses across time zones in the online environment, their views on the changes to international student visa regulations by the U.S. government, and how they felt the university supported them through these challenging times.

As I write this article, I am still working remotely, taking doctoral courses online, and continuing to homeschool my children. I believe that my own students are in a place where they know they are supported and continue to feel a sense of community despite our physical distance. I look forward to moving forward with my research and hope that my findings will include all participants feeling supported, valued, and knowing their institution navigated this time with their best interest in mind.

\section{Virtual Village}

Similar to the study described above, my work also focused on international education. I first became acquainted with Senegal High School (a pseudonym) in 2019 when I visited Senegal as a Fulbright Fellow. During my fellowship, I had many opportunities to learn about Senegal's languages and culture and teach lessons with my host teacher. We were invited to many homes for meals and ataya-the traditional tea ceremony of sorts, that usually occurs after lunch or dinner. During my second visit to Senegal, I lived in the home of my host teacher and participated in Senegalese life as a member of the family. I was thrilled to experience and learn more about Senegalese culture and traditions. We traveled to historic sites and important 
cities around the country and I taught at the village high school. Not only that, but I attended a wedding and a baby naming ceremony in a village situated just off the government road. Reconnecting with teachers, administrators, and community members not only reaffirmed my desire to study the school's learning community but moved me closer to becoming a member of their extended family. I was eager to return a third time to officially begin gathering data.

My proposed research design was a case study. I initially wanted to know more about Senegal High School, the students, and the people who support them. Specifically, I wanted to understand how parents, families, and community members support their children's education and the factors that empower the parents, families, and communities to act as advocates on the students behalf. Using a conceptual framework that includes Ubuntu (Metz, 2007), my research would consist mainly of interviews, observations, and document and artifact analysis. In addition to interviewing parents, family members, and community members, I would also interview teachers and administrators of Senegal High School, a total of approximately 20 individuals.

When COVID-19 began sweeping across the globe, forcing countries to close their borders, I felt that my study was in danger. I was no longer sure that the study would be feasible for my dissertation, but I had come too far to give up. The basis of the research would remain the same, but the methodology would require several pivots, some creativity, collaboration, and trust.

The major pivot in my study related to the methodology. First, because I could no longer travel to Senegal to physically collect data, I needed the support of a research assistant-someone in Senegal who could conduct the interviews, collect documents and artifacts, share the data and debrief with me. I also knew that this task was going to be demanding, and the assistant had to be willing to devote the time to complete the assignment, which would include at least 40 hours. My former host teacher graciously offered to support the study; this researcher assistant completed the necessary training and passed the necessary assessments to participate in research with human subjects. Additionally, I would have to incorporate the use of technology wherever possible, to be "present" in the interviews with the participants (Matthews \& Cramer, 2008), and to debrief with my research assistant. As a result, I included a prerecorded video in the interview procedure where I introduced myself, described the nature and purpose of the study, and thanked them for considering participating in the study. This way, the participants would not only have a name but a face associated with the questions that my research assistant would ask. Furthermore, because we had time, thanks to the quarantine, my dissertation committee encouraged me to increase the robustness of the study by including student voices. I decided to add student interviews to the data collection to hear students' perspectives about how their education is supported. This decision, however, added an additional layer of approval and level of scrutiny to my already complicated study. My research protocol would need a full IRB review, which meant more waiting. In this time of waiting, however, I had opportunities to consult with my new extended family in Senegal to clarify concepts, constructs, and cultural expressions when revising the interview protocol. I had time to work with my colleagues more than 6,000 miles away and rely on others to secure the appropriate permissions to conduct the study. I had time to think and be explicitly clear about the research protocol because my research assistant would be gathering data. I knew that it would be critically important that the interview protocol not only address the research questions but connect to the conceptual framework, without exerting additional effort.

Ultimately, research in the time of COVID-19 has taught me a wealth of lessons that have impacted not only my practice as a researcher but my practice as a classroom teacher as well. This process has taught me the art of practicing patience. I frequently had to revise, rethink, or reconsider methodological approaches, and instead of being stymied by the roadblocks, I learned that there is always a way to get something accomplished. This process has also taught me to look for and celebrate the capital in others (Coleman, 1988). I often sought the wisdom and expertise of others so that my study could be approved. And, as much as I cling to the paper and pencil, I have learned that technology can provide practical solutions to challenges that seem daunting. Research in the time of COVID-19 has become more than just an attempt to conduct an international case study about one school surrounded by several villages and has challenged me to recognize and rely on others' wisdom, expertise, and various forms of capital every day.

\section{IMPLICATIONS}

Navigating the dissertation in practice process during a global pandemic led to shifts in research topics and methodologies, as well as to our needs as doctoral students. We relied heavily on our dissertation chairs and program faculty to guide us towards alternative research approaches that would maintain our prepandemic plans as much as possible. For example, when in-person interactions were no longer feasible, faculty recommended replacing observations with document analysis. Similarly, when one researcher's inability to travel to Senegal threatened to upend her study, the chair suggested hiring a Senegalese research assistant who would conduct the interviews for her. These troubleshooting conversations mostly took place via Zoom and email, adding another layer of change during the dissertation process. Ultimately, both students and faculty needed to be nimble and adaptable, working together to find quick, creative solutions to seemingly insurmountable challenges.

Scholarly practitioners are strategically positioned to respond to their contexts in ways that are informed by their experiences, knowledge of their communities of practice, and scholarly work. Furthermore, we all possess elements of what Collins (1991) presents as the ethic of caring, an epistemological dimension used by African American women. Elements of this ethic include an emphasis on individual uniqueness which respects human beings as unique beings. All researchers demonstrated a high respect for our participants and the context of our research. The second element of this ethic involves emotions in dialogue, meaning the understanding that emotions and thoughts are inextricably connected and cannot be separated. Each researcher created space to hold the emotional toll of the pandemic on our participants and devised ways to include this aspect of the current conditions in pre-interviews or during check-in sessions. The third element of this ethic is empathy. We were empathetic to the difficulties faced by our participants and communities. Their high level of empathy is what motivated us to pivot during the pandemic as a means to acknowledge the impact of the pandemic on our scholarly work. Finally, there is an element of personal accountability for the knowledge that is being created that is deeply rooted in values and ethics. "Neither emotion nor ethics is subordinated to reason. Indeed, emotion, ethics and reason are used 
as interconnected, essential components in assessing knowledge claims" (Collins, 1991, p. 219).

Only one of the authors identifies as African American. However, we are all women who come to our scholarly work from a social justice stance that is very much informed by the intersection of our multiple identities-social justice female leaders working in contexts that support marginalized groups. As we embrace the communities for which we work, our identities are steeped in the challenges our students and educational communities face. It is in fact that saturation that informs our liberatory research practices; we all bear witness to the resilience and shared humanity palpable in our educational organizations.

\section{REFERENCES}

Cammarota, J., \& Fine, M. (Eds.). (2008). Revolutionizing education: Youth participatory action research. Routledge.

Carnegie Project on the Education Doctorate (CPED) (2019). The CPED framework. https://cped.memberclicks.net/the-framework

Coleman, J. S. (1988). Social capital in the creation of human capital. American Journal of Sociology, 94, Supplement S95-S120.

Collins, P. H. (1991). Black feminist thought: Knowledge, consciousness, and the politics of empowerment: Vol. 2. Perspectives on gender. Routledge.

Frazier, S. L., Mehta, T. G., Atkins, M., Gibbons, R. D., Kim, J. B., Chapman, J. E., Schoenwald, S. K., Cua, G., \& Ogle, R. R. (and the LINKS Center). (2015). The social context of urban classrooms: Measuring student psychological climate. Journal of Early Adolescence, 35(5-6), 759-789. http://doi.org/10.1177/0272431615570056

Galletta, A. \& Cross, W. E. (2013). Mastering the semi-structured interview and beyond: From research design to analysis and publication. NYU Press.

Institute of International Education (IIE, 2019). International student enrollment trends, 1948/49-2018/2019. Open Doors Report on International Educational Exchange. http://www.iie.org/opendoors

Levitt, J. M., Saka, N., Romanelli, L. H., \& Hoagwood, K. (2007). Early identification of mental health problems in schools: The status of instrumentation. Journal of School Psychology, 45(2), 163-191. https://doi.org/10.1016/j.jsp.2006.11.005

Mann, C. \& Stewart, F. (2000). Internet communication and qualitative research: $A$ handbook for research online. Sage.

Matthews, J., \& Cramer, E. P. (2008). Using technology to enhance qualitative research with hidden populations. Qualitative Report, 13(2), 301-315. https://nsuworks.nova.edu/tqr/vol13/iss2/10

Metz, T. (2007). Toward an African moral theory. Journal of Political Philosophy, 15(3), 321-341. https://doi.org/10.1111/j.14679760.2007.00280.x

Noddings, N. (2013). Caring. A relational approach to ethics and moral education, 2nd ed. University of California Press.

Osterman, K. (2000). Students' need for belonging in the school community. Review of Educational Research, 70(3). 323-367. https://doi.org/10.3102/00346543070003323

Patel, L. (2016). Decolonizing educational research: From ownership to answerability. Routledge.

Rao, P. (2017). Learning challenges and preferred pedagogies of international students: A perspective from the United States. International Journal of Educational Management. 31(7). 1000-1016. https://doi.org/10.1108/IJEM-01-2016-0001

Sandoval, Ch. (2000). Methodology of the oppressed: Vol. 18. Theory out of bounds. University of Minnesota Press.

Sherry, M., Thomas, P., \& Chui, W. H. (2010). International students: A vulnerable student population. Higher Education, 60, 33-46. https://doi.org/10.1007/s10734-009-9284-z
Solorzano, D. G., \& Yosso, T. J. (2002). Critical race methodology: Counterstorytelling as an analytical framework for education research. Qualitative Inquiry, 8, 23-44. http://doi.org/10.1177/107780040200800103

Storey V. A. \& Maughan B. D. (2016). Dissertation in practice: Reconceptualizing the nature and role of the practitioner-scholar. In V.A. Storey (Eds.), International perspectives on designing professional practice doctorates (pp. 213-232). Palgrave Macmillan. https://doi.org/10.1057/9781137527066_13

U.S. Customs and Immigration Enforcement (ICE) (2020, July 6). SEVP modifies temporary exemptions for nonimmigrant students taking online courses during fall 2020 semester. https://www.ice.gov/news/releases/sevp-modifies-temporary-exemptionsnonimmigrant-students-taking-online-courses-during 